\title{
Managing Waste through the Internet of Things (IoT)
}

\author{
Stanislas Bigirimana \\ Department of Computer Science and Information Systems \\ College of Business, Peace, Leadership and Governance \\ Africa University \\ PO BOX 1320 Mutare \\ Zimbabwe \\ sbigirimanaus@yahoo.com or bigirimanas@africau.edu
}

\begin{abstract}
Waste management has become a topical issue in various parts of the world. Conceptually, there is confusion between waste management and garbage collection in some countries. Waste management includes various steps such as prevention, collection (with separation of various forms of waste), recycling, reuse, and disposal of toxic waste. An examination of current literature shows the most waste management models are fragmented. Hence, this papaer advocates dynamic and integrative models which would amount to transforming trash into cash by addition value to waste. The concept of the Internet of Things (IoT) and corollary concepts such as smart cities, invites for technology enhanced waste management systems and in the current state of knowledge, a mobile app that local municipalities can use for waste management purposes can be developed.
\end{abstract}

Key words: waste management, Internet of Things (IoT), Local Municipalities

\section{Introduction}

Managing waste in developing countries poses several challenges. Conceptually, there is a lot of confusion between waste management and garbage collection or disposal. Collection and disposal are only steps in the waste management process. Waste management comprises six activities, namely, prevention, collection (separation of biodegradable, metal, plastic, and paper waste), removal, recycling, reuse, and safe disposal of toxic and dangerous waste. These activities are carried at various levels including the household, institutions, community, and industrial level. A systematic analysis of a waste management system requires as interdisciplinary approach because waste management includes a matrix of activities and processes that are supported by infrastructure, social, political, administrative structures, and a culture influences both individual and collective behavior.

\section{The Fragmentation of Current Models}

Existing literature still consider the various activities in waste management in isolation. Nuortio et al. (2006) focused on route planning and scheduling while Ghose and Dikshit (2006) studied A GIS based transportation model for solid waste disposal-A case study on Asansol municipality, in India. Zamorano et al. (2009) focus on a planning scenario for the application of geographical information systems in municipal waste collection in the city of Churriana de la Vega (Granada, Spain) while Tavares et al. (2008) studied the optimisation of Municipal Solid Waste (MSW) collection routes for minimum fuel consumption using 3D GIS modelling. Tavares et al. (2008) limited themselves to collection and transportation instead of the whole process. Anagnostopoulos and Zaslavsky (2014) also focus on collection with their primary interest being effective waste collection with shortest path semistatic and dynamic routing. Marshall and Farahbakhsh (2013) noted that engineered systems have been used to help SWM agencies in industrialized countries since the 1960s, collection and removal dominate the SWM sector in developing countries. Moreover, In industrialized countries, public health, environment, resource scarcity, climate change, and public awareness and participation have acted as SWM drivers towards the current paradigm of integrated SWM. However, urbanization, inequality, and economic growth; cultural and socio-economic aspects; policy, governance, and institutional issues; and international influences have complicated SWM in developing countries (Marshall and Farahbakhsh, 2013). Therefore, there is a need of of founding new SWM approaches for developing country contexts in post-normal science and complex, adaptive systems thinking (Marshall and Farahbakhsh, 2013). Systems thinking is the underlying approach of this study because of the need to go beyond fragmented approaches. There is a need to tackle waste management holistically starting by the mindsets of the people i.e. in some developing countries it is considered normal to throw liter at public place and sensitizing people

ACRID 2017, June 20-21, Victoria Falls, Zimbabwe

Copyright (C) 2017

DOI 10.4108/eai.20-6-2017.2270818

314 
at all levels on the importance of proper waste management and its economic, health, environmental, aesthetic and cultural importance. Perera et al. (2014) rightly pointed to the need of sensing as a service model for smart cities supported by Internet of Things (IoT). Abarca-Guerrero et al. (2012) tackled Solid waste management challenges for cities in developing countries. Abarca-Guerrero et al. (2012) noted that solid waste management is a challenge for the cities' authorities in developing countries mainly due to the increasing generation of waste, the burden posed on the municipal budget as a result of the high costs associated to its management, the lack of understanding over a diversity of factors that affect the different stages of waste management and linkages necessary to enable the entire handling system functioning. Abarca-Guerrero et al. (2012)'s study provided a comprehensive list of stakeholders that are relevant in the waste management systems and a set of factors that reveal the most important causes for the systems' failure.Medvedev et al. (2015) brought to the forefront the idea of waste management as an IoT-enabled service in smart cities.

\section{Towards Dynamic and Integrative Models}

This study aims at suggesting a dynamic and integrative model of waste management in developing countries that would be supported by the Internet of Things (IoT). This model is based on the fact that waste management is a complex and multi-level process. It is a matrix that comprises the following:

\begin{tabular}{|c|c|c|c|c|}
\hline LEVEL & \multicolumn{3}{|c|}{ ACTIVITY } & OUTCOMES \\
\hline Individual & Prevention & Collection & Reuse & \multirow[t]{2}{*}{ Reduced Waste } \\
\hline Household & & Biodegradable & & \\
\hline Community & & Paper & Recycle & \multirow{2}{*}{$\begin{array}{l}\text { Income Generation } \\
\text { (Poverty Reducation) }\end{array}$} \\
\hline City or District & & Plastic & $\begin{array}{l}\text { (Compost } \\
\text { Manufacturing) }\end{array}$ & \\
\hline Province or State & & Metal & & \multirow{3}{*}{$\begin{array}{l}\text { Organic Farming (Food } \\
\text { Security) }\end{array}$} \\
\hline National & & Glass & & \\
\hline Regional & & Toxic & Dispose & \\
\hline Global & & & & \multirow{3}{*}{$\begin{array}{l}\text { Employment Creation } \\
\text { (Exchange of Trash or } \\
\text { Cash) }\end{array}$} \\
\hline ORGANISATION & & Trucking & Selling and Exporting & \\
\hline & \multirow[t]{4}{*}{ Institute } & Transport & Metal \& Glass Waste & \\
\hline & & $\begin{array}{l}\text { Bins import or } \\
\text { Manufacturing }\end{array}$ & $\begin{array}{l}\text { Compost } \\
\text { Manufacturing, } \\
\text { Making plastic } \\
\text { household appliances } \\
\text { Disposal }\end{array}$ & $\begin{array}{l}\text { Improvement of Hygiene } \\
\text { (Destruction of mosquito } \\
\text { breeding sites and } \\
\text { reduction of water born } \\
\text { diseases) }\end{array}$ \\
\hline & & & & $\begin{array}{l}\text { Improvement of City } \\
\text { Aesthetics (Possible } \\
\text { Tourism Development) }\end{array}$ \\
\hline & & & & $\begin{array}{l}\text { Reduced Criminality } \\
\text { (Street children collecting } \\
\text { waste for food or cash) }\end{array}$ \\
\hline
\end{tabular}

The unprecedented development and diffusion of electronic computers and other information and communication technologies (ICTs) provides opportunities for institutions involved in waste management such as local municipalities and private actors to create waste management systems which are financially viable, socially inclusive, ethically sound and environmentally sustainable. This paper argues that these waste management systems (some of them can be commercial if managed by private investors) can be designed following two principles debureaucratisation and virtualization. This implies integrating information and communication technologies infrastructure, with the necessary structure and corporate culture. By Information and Communication Technologies, 
the researcher refers to input, output, processing, storage, networking, and mobile devices. This implies turning the whole waste management system into a viable value chain. De-bureaucratization implies a client-based approach which takes into account changes in demographics and psychodynamics. For instance, in many developing countries there a great need for a change of mindset. Many inhabitants do not consider throwing litter on public spaces as a problem. There is a need for sensitization. Henceforth, any sound waste management system should start by prevention. Whenever possible waste should not be generated at all. This prevention stage is represented by the red triangle in the diagram and it cuts across individuals, households, communities, nations and the globe at large.

The second stage is collection. Conceptually there is a confusion between waste management and garbage collection. The latter is already in existence in several municipalities but the current limitation is that at the household and collection levels, there is no separation of various types of waste. Trucks collect biodegradable, plastic, glass and metal waste together and dispose them at a dumpsite. There is no mechanism for separation of various sorts of waste or recuperation of what can be recycled or reused. The separation of waste needs to be effected at household level as it is done in other parts of the world. This is difficult to reinforce given the fact that in various countries, the population may not be able to afford the stiff penalties imposed in developed countries. However, separation of waste can be achieved by incentivizing it i.e. giving it a commercial value. If for instance, a waste management system is managed on commercial terms, there is a possibility of creating businesses such as bin manufacturing or importance but also it is market for trucking and transportation of waste to various destination. In many instances, some wasted objects may be reused but where it is not possible biodegradable waste can be used to create a compost manufacturing business which can have a greater impact in promoting organic agriculture. There is a need for a paradigm shift from considering waste as a challenge to considering it as an opportunity. Toxic waste should be properly disposed while metal waste can still be used as input in various industries. Likewise, plastic waste can be used in manufacturing various objects of domestic and industrial usage.

The business model we are suggesting is based on the concept of an information-based organization that foster interaction, partnership and horizontal relations between various stakeholders (Quinn et al. 1996: 350). That is why it is important to determine beforehand the level of operationalization. Various rows in the diagram show various possible levels of operationalization such as the individual, the household, the community, the city or district, the province or state, national, regional, and global levels. In some levels operationalization needs to be incremental. Virtualization implies fast, real-time, online and interactive functions that the internet and related technologies brought in the marketplace. An "informated" business ecosystem does not render itself to rigid classifications easily. This implies an amorphous business organisational model that integrates the different models in a complex process that creates value by integrating technology, people, and other demographics and psychodynamics in a way that satisfies the customer. This model is called in contemporary business jargon, the "virtual organization" (Hedbeg 1997). The author is of the view that the concept of the Internet of Things (IoT) can contribute to the accomplishment of these tasks through its use of multiple equipment and multimedia features.

\section{The Role of the Internet of Things}

The Internet of Things (IoT) is an umbrella concept depicting the inter-networking of physical devices, vehicles (also referred to as "connected devices" and "smart devices"), buildings, and other items - embedded with electronics, software, sensors, actuators, and network connectivity that enable these objects to collect and exchange data (Brown, 2016; ITU, 2015). According to a feature article sponsored by Verizon (2014) in the Harvard Business Review, the Internet of Things (IOT) is now fact and not faction. The IoT allows objects to be sensed or controlled remotely across existing network infrastructure (Verizon, 2014). This remote sensing and controlling leads to more direct integration of the physical world into computer-based systems resulting in improved efficiency, accuracy and economic benefit thanks to reduced human intervention (Vermesan\&Friess, 2013; Lopez Research, 2015; Santucci, n.d.,Mattern, F., Floerkemeier, C., n. d., Reddy, 2014; Lindner, 2015). On a wide scale, When IoT is augmented with sensors and actuators, the technology becomes an instance of the more general class of cyber-physical systems, which also encompasses technologies such as smart grids, smart homes, intelligent transportation and smart cities(Evans, 2011; Hwang\&Choe, 2013; Zanella et al., 2014; ). It is in the perspective of building smart cities that the IoT can be used for waste management purposes. The IoT works through an IP address allocated to each object. In other words, Each thing is uniquely identifiable through its embedded computing system but is able to interoperate within the existing Internet infrastructure (Evans, 2011). The Internet of Things can tackle traditional issues such as Smart Energy Management Systems (Violino, 2014, Hogan, 2014). Smart Energy Management Systems involves processes such as home automation (also known as smart home devices) such as the control and automation of lighting, heating (like smart thermostat), ventilation, air conditioning (HVAC) systems, and 
appliances such as washer/dryers, robotic vacuums, air purifiers, ovens or refrigerators/freezers that use Wi-Fi for remote monitoring (Violino, 2014, Hogan, 2014). The Internet of Things is already used in various areas of city management and in our context, a mobile app connecting the various devices can de designed.

\section{References}

Benjamin A. M., Beasley J. E., "Metaheuristics for the waste collection vehicle routing problem with time windows, driver rest period and multiple disposal facilities", Journal of Computers \& Operations Research, vol. 37 (12), pp. 2270-2280, December, 2010.

Brown, Eric (13 September 2016). "Who Needs the Internet of Things?". Available at https://www.linux.com/news/who-needs-internet-thingsLinux.com. Retrieved 15 March 2017.

Ghose M. K., Dikshit A. K., S. K. Sharma, "A GIS based transportation model for solid waste disposal - A case study on Asansol municipality", Journal of Waste Management, vol. 26 (11), pp. 1287-1293, January, 2006.

Guerrero L. A., Maas G., Hogland W., "Solid waste management challenges for cities in developing countries", Journal of Waste Management, vol. 33 (1), pp. 220-232, January, 2013.

Hedberg, B.; Dahlgreen, G. ; Hansson, J. ; Olve N-G. 1988 Virtual Organisations and Beyond: Discovering Imaginary Systems, Wiley and Sons, New York.

Hogan, Michael. "The 'The Internet of Things Database' Data Management Requirements"

Hwang, J., Choe, Y. (2013) "Smart Cities Seoul: a case study" available at https://www.itu.int/dms_pub/itut/oth/Ob/15/TOB150000153301PDFE.pdf accessed 15 March 2017.

ITU (2015) "Internet of Things Global Standards Initiative". Available at http://www.itu.int/en/ITUT/gsi/iot/Pages/default.aspx accessed 15th March 2017.

Lindner, T. (2015)."The Supply Chain: Changing at the Speed of Technology" available at https://connectedworld.com/the-supply-chain-changing-at-the-speed-of-technology/ accessed on 15 March 2017.

Lopez Research (2013)"An Introduction to the Internet of Things (IoT)" available at http://www.cisco.com/c/dam/en_us/solutions/trends/iot/introduction_to_IoT_november.pdf accessed 15 March 2017.

Marshall R. E., Farahbakhsh K., "Systems approaches to integrated solid waste management in developing countries", Journal of Waste Management, vol. 33 (4), pp. 988-1003, April, 2013.

Mattern, F., Floerkemeier, C. (n.d.) "From the Internet of Computers to the Internet of Things"http://www.vs.inf.ethz.ch/publ/papers/Internet-of-things.pdf accessed on 15 March 2017.

Nuortio T., Kytojoki J., Niska H., Braysy O., "Improved route planning and scheduling of waste collection and transport", Journal of Expert Systems with Applications, vol. 30 (2), pp. 223-232, February, 2006.

Quinn, J.; Andersen, P.; and Finkelstein, S. (1996) Managing Professional Intellect: Making the most of the best. Harvard Business Review. March

Santucci, Gérald. "The Internet of Things: Between the Revolution of the Internet and the Metamorphosis of Objects" European Commission Community Research and Development Information Service available at http://cordis.europa.eu/fp7/ict/enet/documents/publications/iot-between-the-internet-revolution.pdf accessed on 15 March 2017. 
Tavares G., Zsigraiova Z., Semiao V., Carvalho M. G., "Optimisation of MSW collection routes for minimum fuel consumption using 3D GIS modeling", Journal of Waste Management, vol. 29 (3), pp. 1176-1185, March, 2009.

Verizon (2014)"Internet of Things: Science Fiction or Business Fact?".Harvard Business Review. November 2014 available at https://en.wikipedia.org/wiki/Internet_of_things\#cite_note-4. Retrieved 15 March 2017.

Vermesan, O., Friess, P. (2013).Internet of Things: Converging Technologies for Smart Environments and Integrated Ecosystems, Aalborg, Denmark: River Publishers.

Violino, B. (2014) "The 'Internet of things' will mean really, really big data" available at http://www.infoworld.com/article/2611319/computer-hardware/the--internet-of-things--will-mean-really-really-big-data.html accessed on 15 March 2015.

Zamorano M., Molero E., Grindlay A., Rondriquez M. L., Hurtado A., Calvo F. J., "A planning scenario for the application of geographical information systems in municipal waste collection: A case of Churriana de la Vega (Granada, Spain)”, Journal of Resources, Conservation and Recycling, vol. 54 (2), pp. 123-133, December, 2009.

Zanella, A., Bui, N., Castellani, A. ,Vangelista, L., Zorzi, M. (2014). "Internet of Things for Smart Cities". IEEE Internet of Things Journal. 1 (1): 22-32. 